Jacek Kriegseisen

Instytut Historii Sztuki, Uniwersytet Gdański

ORCID: 0000-0001-6272-6737

\title{
Nieznany złotniczy znak miejski Gdańska z czwartej ćwierci XVII w.
}

DOI: https://doi.org/10.26881/porta.2020.19.06

Znaki złotnicze, w tym szczególnie znaki miejskie używane na terenie Rzeczypospolitej, są od końca XIX w. przedmiotem zainteresowania wielu badaczy, ponieważ ułatwiają przypisanie zabytkowych sreber konkretnemu ośrodkowi złotniczemu. Ponadto można na ich podstawie określić dokładniejszy czas powstania zabytku, jeśli wyniki jego analizy stylistycznej okazują się zbyt szerokie. Największe zasługi spośród badaczy polskich w zakresie opracowania tego tematu w ostatnich kilkudziesięciu latach położył Michał Gradowski, który zweryfikował i opublikował wiele znaków dotąd nieznanych lub nie dość szczegółowo opisanych ${ }^{1}$.

Jak wskazują zachowane zabytki, puncyny przeznaczone do wybijania znaków miejskich na srebrach były używane - w zależności od intensywności wykorzystania i stopnia ich zużycia - przez krótszy (rok lub kilka lat) lub dłuższy czas (nawet kilkanaście lat). Dlatego też trudne lub niemożliwe było ustalenie, który (zmieniający się co roku) starszy cechowy, uprawniony do wybijania znaku miejskiego, dokonał oznaczenia wyrobu. Problem ten znikł dopiero po wprowadzeniu w Gdańsku w 1730 r. nakazu wybijania kontrasygnaty, czyli dodatkowego znaku kontrolnego. Jak zasugerował Gradowski, być może to właśnie trudności z ustaleniem okresu działalności kontrolera cechowego sprawiły, że puncyna służąca do wybijania znaku obowiązującego w Gdańsku została - w okresie od 1674 lub 1675 r. do końca lat osiemdziesiątych XVII w. (o którym będzie mowa ${ }^{2}$ - kilkakrotnie „uszczerbiona” (il. 1a-e).

Pierwsza zmiana polegała na takim nacięciu puncyny, że w wybijanym znaku miejskim, w prawej części łukowatego zwieńczenia cechy widoczne było prostokątne wcięcie ${ }^{3}$. Szczerba ta jest wyraźna, ale w praktyce często zlewa się z prawym fleuronem korony nad herbem miasta (il. 1b). Druga modyfikacja nastąpiła wraz z wykonaniem cienkiego nacięcia, lekko pochylonego w prawo,

Michał Gradowski, Znaki na srebrze. Znaki miejskie i państwowe używane na terenie Polski w obecnych jej granicach, Warszawa 2010 (tamże dalsza szczegółowa literatura).

2 Ibidem, s. 84, nr 5A.

3 Ibidem, s. 84, nr 5B. 
Jacek Kriegseisen

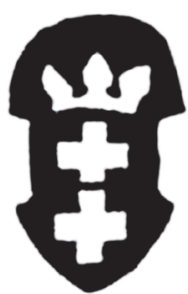

il. $1 \mathrm{a}$

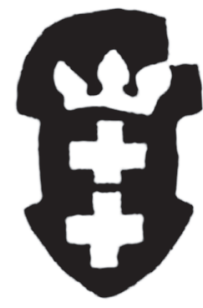

il. $1 \mathrm{~b}$

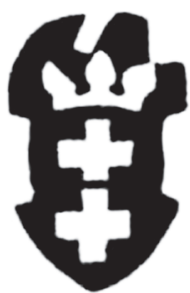

il. $1 \mathrm{c}$

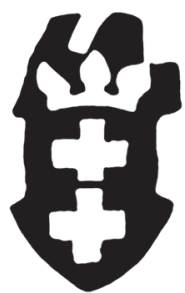

il. $1 \mathrm{~d}$

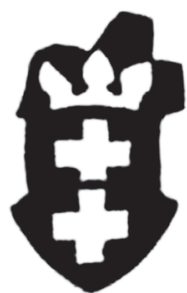

il. $1 \mathrm{e}$

Il. 1. Wersje znaku miejskiego Gdańska używanego około 1674-1689: il. 1a (5A) około 1674-1675; il. 1b (5B) - około 1676-1678; il. 1c (5C) - około 1682; il. 1d (5E) - około 1683 - przed 1688; il. 1e (5D) - przed 1689, repr. za: Michał Gradowski, Znaki na srebrze. Znaki miejskie i państwowe używane na terenie Polski w obecnych jej granicach, Warszawa 2010, s. 84 , poz. $5 \mathrm{~A}-\mathrm{D}$

w środkowej części łukowatego zwieńczenia znaku (il. 1c). Trzecia zmiana, dotychczas niezarejestrowana, polegała na głębokim ścięciu lewej górnej części cechy w ten sposób, że w zwieńczeniu znaku pozostały dwa „zęby”: lewy cieńszy, i prawy - zdecydowanie grubszy ${ }^{5}$ (il. 1d). Czwarta i zapewne ostatnia zmiana została wykonana przez wycięcie owego cieńszego „zęba”, co spowodowało, że w zwieńczeniu znaku pozostał tylko jeden - ten grubszy ${ }^{6}$ (il. 1e).

$\mathrm{W}$ ten sposób jedna puncyna, odpowiednio modyfikowana, posłużyła do wybicia znaków w pięciu odmianach. W dotychczasowych publikacjach nie wyróżniono odmiany znaku „dwuzębnego”, któremu, łamiąc utrwaloną już kolejność alfabetyczną ustaloną przez Gradowskiego, trzeba nadać nr 5E.

Znak nr 5A (il. 1a), czyli podstawowa wersja puncyny (bez nacięć), znany Gradowskiemu z kubka ${ }^{7}$ wykonanego przez Petera Rohde (Röde) II (czynny w latach 1654-1694; wdowa po nim prowadziła warsztat prawdopodobnie nawet do 1702 r. ${ }^{8}$ ), był w użyciu krótko - zapewne około 1674-1675 r.

4 Ibidem, s. 84, nr 5C.

Ibidem. Brakuje jej oczywiście w zestawieniu przedstawionym przez autora.

Ibidem, s. 84, nr 5D.

Ibidem, s. 89. Własność prywatna.

8 Eugen von Czihak, Die Edelschmiedekunst früherer Zeiten in Preussen, Tl. 2, Westpreussen, Leipzig 1908, s. 62, poz. 357; Michał Gradowski, Agnieszka Kasprzak-Miler, Złotnicy na ziemiach pótnocnej Polski, cz. 1, Województwo pomorskie, kujawsko-pomorskie i warmińsko-mazurskie, Warszawa 2002, s. 107-108, poz. G 446; Jacek Kriegseisen, Słownik złotników gdańskich czynnych w latach 1700-1816 [w:] „...tyżek srebrnych dwa tuziny”. Srebra domowe w Gdańsku 1700-1816 [katalog wystawy], red. Jacek Kriegseisen, Ewa Barylewska-Szymańska, współpraca Wojciech Szymański, Dom Uphagena - Oddział Muzeum Historycznego Miasta Gdańska, Gdańsk 2007, s. 183 , poz. 135 . 
Wykorzystanie znaku nr 5B (il. 1b) zostało potwierdzone inskrypcyjnie w 1676 r. na kielichu przechowywanym w katedrze w Oliwie ${ }^{9}$, a wykonanym przez Ernsta Kadaua I (czynny w latach $1643-1679^{10}$ ). Poza tym znak taki wybito na misie ${ }^{11} \mathrm{z}$ warsztatu Jacoba Beckhausena (czynny w latach 1678-1705 ${ }^{12}$ ) i kuflu ${ }^{13}$ roboty Johanna Gottfrieda Holla (czynny w latach 1678-1690; wdowa po nim prowadziła warsztat jeszcze w $1701 \mathrm{r} .^{14}$ ), którzy rozpoczęli działalność w 1678 r. A zatem znak był w użyciu w latach 1676-1678, a zapewne i dłużej.

Wariant nr 5C (il. 1c) widnieje na pucharze ${ }^{15}$ wykonanym przez Christiana Pichela (Pichgiela) I (czynny w latach 1682-1700; wdowa po nim prowadziła warsztat do 1713 lub nawet do $1715 \mathrm{r}^{16}$ ), który w $1682 \mathrm{r}$. otrzymał obywatelstwo miasta i mógł otworzyć warsztat. Znak ten był więc w użyciu około $1682 \mathrm{r}$.

Dotychczas nieodnotowany znak, chronologicznie następny - nr 5E (il. 1d), odnaleziono na kilku zabytkach, jednak prawie zawsze jego drobne elementy (przede wszystkim lewy „ząb”) były na tyle zniekształcone lub uszkodzone, że ich przerysowanie nie dawałoby bezwzględnej pewności co do rzeczywistego kształtu cechy. Jednoznaczne jego rozpoznanie było możliwe dzięki odnalezieniu tej wersji znaku, szczęśliwie dobrze zachowanego, ale tylko w swojej górnej części (il. 2), na barokowej stopie ${ }^{17}$ wykonanej przez Ernsta Kadaua II (czynny w latach 1675-1690; wdowa po nim prowadziła warsztat jeszcze w $\left.1701 \mathrm{r}^{18}\right)$, dekorowanej

9 Gradowski, Znaki na srebrze..., s. 89, 101, przyp. 14.

10 Czihak, Die Edelschmiedekunst..., s. 60, poz. 338; Gradowski, Kasprzak-Miler, Złotnicy..., s. 101-102, poz. G 417 .

11 Sankt Petersburg, Ermitaż, nr inw. Э 8737, zob. W blasku srebra... Srebra z XVI-XIX w. z ziem Rzeczypospolitej Obojga Narodów i współczesnej Polski ze zbiorów muzeów rosyjskich: Ermitażu w Sankt Petersburgu, Muzeów Moskiewskiego Kremla i Muzeum Historycznego w Moskwie [katalog wystawy], red. Anna Saratowicz-Dudyńska, Zamek Królewski w Warszawie, Warszawa 2006, s. 71-72, kat. 26, il. oprac. Marina N. Łopato (tamże wcześniejsza literatura); Gradowski, Znaki na srebrze..., s. 89, 101, przyp. 15.

12 Czihak, Die Edelschmiedekunst..., s. 65, poz. 377; Gradowski, Kasprzak-Miler, Złotnicy..., s. 113, poz. G 472; Kriegseisen, Słownik złotników gdańskich..., s. 157, poz. 7.

13 Moskwa, Muzeum Historyczne, nr inw. ГИМ 50258 ОК 3691, zob. W blasku srebra..., s. 76-77, kat. 30, il. oprac. Tatiana I. Sizowa (tamże wcześniejsza literatura); Gradowski, Znaki na srebrze..., s. 89, 101, przyp. 15.

14 Czihak, Die Edelschmiedekunst..., s. 65, poz. 378; Gradowski, Kasprzak-Miler, Złotnicy..., s. 113-114, poz. G 473 .

15 Moskwa, Muzeum Historyczne, nr inw. ГИМ 882щ ОК 3814, zob. W blasku srebra..., s. 87, kat. 38, il. oprac. Tatiana I. Sizowa (tamże wcześniejsza literatura); Gradowski, Znaki na srebrze..., s. 89, 101, przyp. 16.

${ }_{16}$ Czihak, Die Edelschmiedekunst..., s. 66, poz. 383; Gradowski, Kasprzak-Miler, Złotnicy..., s. 115, poz. G 480; Kriegseisen, Słownik złotników gdańskich..., s. 180, poz. 121.

17 Stopa współcześnie została użyta do zamocowania krzyża relikwiarzowego, przechowywanego w kościele parafialnym pw. św. Katarzyny z Aleksandrii w Braniewie. Panu Andrzejowi Adamskiemu z Braniewa autor jest winien podziękowania za informację o zabytku oraz jego fotografie.

18 Czihak, Die Edelschmiedekunst..., s. 64, poz. 371; Gradowski, Kasprzak-Miler, Złotnicy..., s. 111-112, poz. G 465; Kriegseisen, Słownik złotników gdańskich..., s. 173, poz. 88. 


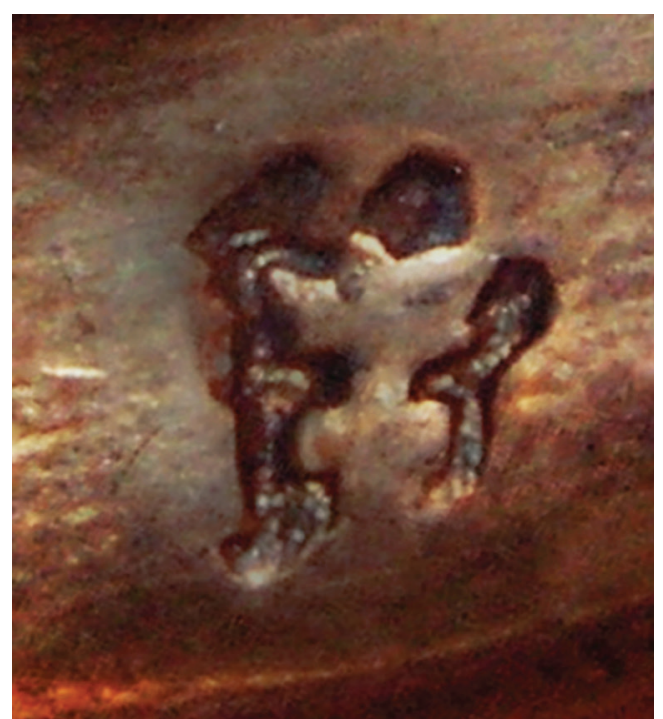

Il. 2. Znak miejski Gdańska używany około 1683 - przed 1688, wybity na barokowej stopie, użytej wtórnie do zamocowania krzyża relikwiarzowego w kościele parafialnym pw. św. Katarzyny z Aleksandrii w Braniewie, fot. Andrzej Adamski repusowanymi przedstawieniami herbów: diecezji warmińskiej, miasta Elbląga i Junosza pod kapeluszem biskupim z dwunastoma chwostami oraz ze skrzyżowanymi za jego tarczą pastorałem i mieczem. To właśnie na podstawie herbu Junosza, którym pieczętował się późniejszy kardynał Michał Stefan Radziejowski, biskup warmiński w latach 1679-1688, zabytek ten można łączyć z jego fundacją ${ }^{19}$. W późniejszych latach, od 1699 do 1711 r., biskupem warmińskim był Andrzej Chryzostom Załuski, który używał takiego samego herbu. Ufundowanie zabytku przez tego biskupa trzeba jednak wykluczyć, ponieważ w latach zasiadania przez niego na stolicy biskupiej warmińskiej wykorzystywano już inne znaki miejskie Gdańska ${ }^{20}$. Kształt znaku potwierdza również cecha wybita na czarce wykonanej przez Johanna Rohde (Röde) II (czynny w latach 1684-1720²1), znajdującej się w zbiorach Westpreußisches

Landesmuseum w Münster $^{22}$ (il. 3). Lata zarządzania diecezją warmińską przez biskupa Michała Stefana Radziejowskiego, wizytacja parafii w Elblągu dokonana przez niego w $1683 \mathrm{r}^{23}$, z którą hipotetycznie można by wiązać powstanie wspomnianego zabytku z Braniewa, w połączeniu z informacją o użyciu cechy nr 5C około 1782 r., pozwalają tej wersji znaku wyznaczyć jedynie szeroki okres funkcjonowania - na lata 1683-1688, jednak w użyciu był zapewne krócej.

19 Na temat działalności kardynała Radziejowskiego jako mecenasa sztuki zob. noty w katalogu wystawy Święto baroku. Sztuka w stużbie prymasa Michała Stefana Radziejowskiego (1645-1705), red. Jerzy Żmudziński, Muzeum Pałac w Wilanowie, Warszawa 2009.

20 Gradowski, Znaki na srebrze..., s. 84, nr 6, 7, 8.

${ }_{21}$ Czihak, Die Edelschmiedekunst..., s. 67, poz. 385; Gradowski, Kasprzak-Miler, Złotnicy..., s. 116, poz. G 483; Kriegseisen, Słownik złotników gdańskich..., s. 183, poz. 134.

22 Münster, Westpreußisches Landesmuseum, nr inw. 2002/02 (BMI), zob. Jutta Reisinger-Weber, Silberschmiedarbeiten im unteren Weichselland. Bestandkatalog der Gold- und Silberschmiedearbeiten im Westpreußischen Landesmuseum, Münster 2016, s. 47, kat. I.09., il. (zapis nazwiska złotnika „Rode”; tamże wcześniejsza literatura). Pani Jutta Reisinger-Weber zechce przyjąć podziękowania za użyczenie fotografii znaku.

23 Sakrę biskupią otrzymał w styczniu 1681 r., a ingres odbył 29 września tego samego roku, zob. Andrzej Rachuba, Radziejowski Augustyn Michał Stefan, internetowy polski słownik biograficzny, https://www.ipsb.nina.gov.pl/a/biografia/michal-radziejowski-prymas-polski [dostęp: 1.03.2020]; Stanisław Achremczyk, Michał Stefan Radziejowski [w:] Poczet biskupów warmińskich, red. Stanisław Achremczyk, Olsztyn 2008, s. 279. 
Znak nr 5D (il. 1e) znajduje się na dzbanie wykonanym przez Christiana Pichgiela $\mathrm{I}^{24}$. Stosowano go najpóźniej, a z pewnością przed 1789 r., kiedy wszedł w użycie inny znak miejski, obowiązujący do $1699 \mathrm{r}$. lub nieco dłużej ${ }^{25}$.

W praktyce znaki wybite jedną i tą samą puncyną mogą znacznie się od siebie różnić. Przyczyny takiego stanu rzeczy mogą być bardzo różne - użycie puncyny uszkodzonej lub zanieczyszczonej drobinkami srebra, co powoduje, że szczegóły jej rysunku stają się nieczytelne, lub wadliwe jej zastosowanie (zbyt słabe, za mocne bądź częściowe jej odbicie). Różnice mogą być spowodowane także zniszczeniem znaku, uszkodzeniami mechanicznymi (zarysowania, czyszczenie), oraz tym, że wyroby wykonane ze srebra wciąż „pracują", ulegając powolnym, lecz nieodwracalnym odkształceniom. Potwierdza to porównanie wielu

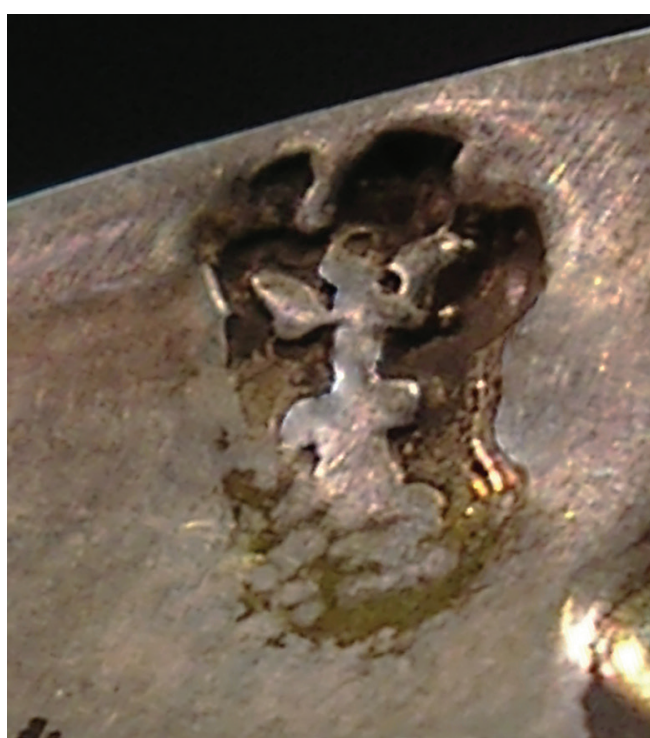

Il. 3. Znak miejski Gdańska używany około 1683 przed 1688 , wybity na czarce, zbiory Westpreußisches Landesmuseum w Münster, fot. Jutta Reisinger-Weber odbitek odmian przedstawionego tu znaku, których kształty w szczegółach nieco odbiegają od rysunków już opublikowanych ${ }^{26}$. Ponieważ jednak nie udało się odnaleźć na tyle dobrze zachowanych cech, które pozwoliłby na wykonanie nowych rysunków, w przypadku znaku nr 5E poprzestaliśmy na razie na odpowiednim zmodyfikowaniu rysunku wykonanego i opublikowanego przez Gradowskiego. Jednak już teraz tak przedstawiony znak oraz zarysowana chronologia użycia w Gdańsku znaków nr 5A-E pozwalają na nieco dokładniejsze datowanie zabytków tutejszego złotnictwa.

\section{Bibliografia}

Achremczyk Stanisław, Michał Stefan Radziejowski [w:] Poczet biskupów warmińskich, red. Stanisław Achremczyk, Olsztyn 2008, s. 275-286.

Czihak Eugen von, Die Edelschmiedekunst früherer Zeiten in Preussen, Tl. 2, Westpreussen, Leipzig 1908.

24 Moskwa, Muzea Moskiewskiego Kremla, nr inw. M3-165, zob. W blasku srebra..., s. 83-84, kat. 36, il. oprac. Natalia W. Raszkowan (tamże wcześniejsza literatura); Gradowski, Znaki na srebrze..., s. 89, 101, przyp. 17.

25 Gradowski, Znaki na srebrze..., s. 84, nr 6.

26 Ibidem, s. 84, nr 5A-D. 
Jacek Gradowski Michał, Znaki na srebrze. Znaki miejskie i państwowe używane na terenie Kriegseisen Polskiwobecnych jej granicach, Warszawa 2010.

Gradowski Michał, Kasprzak-Miler Agnieszka, Złotnicy na ziemiach północnej Polski, cz. 1, Województwo pomorskie, kujawsko-pomorskie i warmińsko-mazurskie, Warszawa 2002.

Kriegseisen Jacek, Słownik złotników gdańskich czynnych w latach 1700-1816 [w:] „...łyżek srebrnych dwa tuziny". Srebra domowe w Gdańsku 1700-1816 [katalog wystawy], red. Jacek Kriegseisen, Ewa Barylewska-Szymańska, współpraca Wojciech Szymański, Dom Uphagena - Oddział Muzeum Historycznego Miasta Gdańska, Gdańsk 2007, s. $155-197$.

Rachuba Andrzej, Radziejowski Augustyn Michał Stefan [w:] Internetowy polski słownik biograficzny, https://www.ipsb.nina.gov.pl/a/biografia/michal- radziejowski-prymaspolski [dostęp: 1.03.2020].

Reisinger-Weber Jutta, Silberschmiedarbeiten im unteren Weichselland. Bestandkatalog der Gold- und Silberschmiedearbeiten im Westpreußischen Landesmuseum, Münster 2016. Święto baroku. Sztuka w służbie prymasa Michała Stefana Radziejowskiego (1645-1705) [katalog wystawy], red. Jerzy Żmudziński, Muzeum Pałac w Wilanowie, Warszawa 2009. W blasku srebra... Srebra z XVI-XIX w. z ziem Rzeczypospolitej Obojga Narodów i współczesnej Polski ze zbiorów muzeów rosyjskich: Ermitażu w Sankt Petersburgu, Muzeów Moskiewskiego Kremla i Muzeum Historycznego w Moskwie [katalog wystawy], red. Anna Saratowicz-Dudyńska, Zamek Królewski w Warszawie, Warszawa 2006.

\section{Unknown Goldsmith's Hallmark of the City of Gdansk from the Fourth Quarter of the $17^{\text {th }}$ Century}

Goldmisth's hallmarks, particularly city ones used within the territory of the PolishLithuanian Commonwealth, have been the object of interest of numerous scholars since the late $19^{\text {th }}$ century. The reason being that not only do they facilitate the attribution of definite historic silverware pieces to a definite goldsmithery centre, but they are also helpful when the results of stylistic analysis prove too wide too define a more precise time of their creation.

Puncheons used to stamp city hallmarks on silver, as is proven by the preserved historic pieces, depending on the intensity of use and degree of wear, were in service either for a shorter time: a year or several years, or a longer time, sometimes some dozen years. For this reason it is hard or almost impossible to ascertain which Guild's Elder, alternating yearly, authorized to stamp the city hallmark, actually marked the product. The problem disappeared only when in Gdansk the duty to stamp a peculiar countersignature, namely an additional control sign, was introduced in 1730 .

The hallmark presented in the paper is a previously unrecorded version of the city of Gdansk's hallmark, whose use can now be dated to 1683-1688, though it was in actual use for a shorter time. However, already with such-defined chronology of the use of hallmarks Nos. 5A-E, a more precise dating of historic pieces of Gdańsk goldsmithery is possible. 